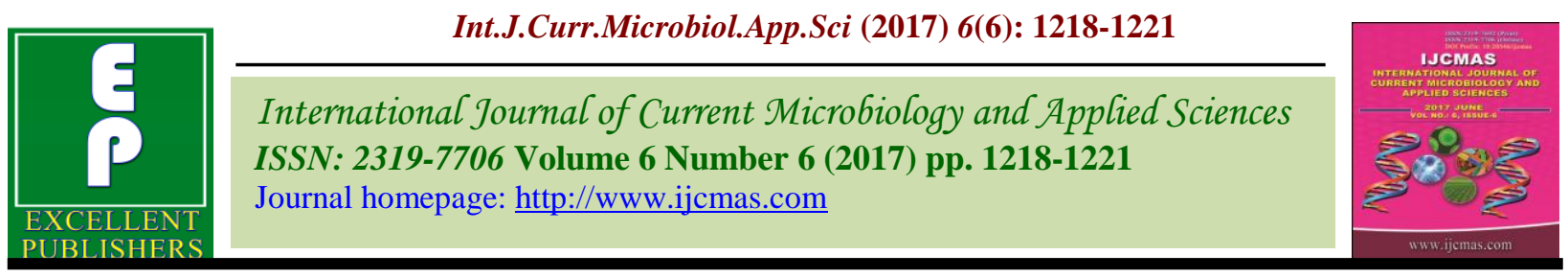

Original Research Article

https://doi.org/10.20546/ijcmas.2017.606.141

\title{
Analysis of Failure of Hydraulic Operated Sorghum Harvester
}

\author{
M.D. Nikam*, S.H. Thakare, V.P. Khambalkar and S.S. Karhale \\ College of Agricultural Engineering and Technology, Dr. P.D.K.V. Akola, (M.S.), India \\ *Corresponding author
}

\section{A B S T R A C T}

\section{Keywords}

Sorghum harvester,

Pareto analysis,

Mechanical failure,

Cutting unit and

Nipping unit.

Article Info

Accepted:

19 May 2017

Available Online:

10 June 2017
The objective of current research work was to carry out field evaluation of sorghum harvester and also conduct the Pareto analysis of sorghum harvester to find out mechanical failure of various parts. The high workload, improper material selection of moving parts, improper clearance, maintenance and repair cause failure of component and many times equipment reliability issues were ignored. All the working components of machine required different level of maintenance throughout the life of machine. In order to minimize operating and maintenance cost, equipment required to be operated at maximum maintenance interval. In order to find out those components of machine which cause failure and contribute most of machine maintenance simple statistical method known as Pareto analysis was used. The sorghum harvester was tested in different field for different varieties of sorghum. During the field performance 46.7 percent and 20 per cent failure/ fault occurred in eccentric drive shaft of nipping unit and cutting unit respectively. Similarly 22.7 percent and 6.6 percent failure/faults occurred in cutter bar of nipping unit and cutting unit respectively.

\section{Introduction}

Harvesting is one of the most important operations in sorghum cultivation, with the highest costs and the biggest work input. Manual harvesting of sorghum is too laborious and needs too many number of workers for considerable period of time. The higher labour cost and lack of availability of labour during harvesting season have led to an increase need of mechanized harvesting.

Sorghum harvesters are machines that carry out all the operations including cutting of cobs at top as well as bottom and convey them. The sorghum is cut at the bottom as well as just below the cobs, then cobs are convey towards the storage box and the stems were conveyed and laid in uniform manner at one side of harvester. Many reasons related to field and crop condition influence the performance of sorghum harvester including moisture content, soil type, humidity, variety, crop yield and operator skill. Mechanical failures in machine may occur regularly in various working parts.

It is necessary to record the time, location, and the reason of failures in order to improve machine performance. The optimization of each component of machine in relation to one another is imperative to make the system 
profitable and reliable for operation. It is obvious that failure cannot be prevented entirely but it is necessary to minimize both its probability of occurrence and the impact of failures when they occur. Thus in order to control and reduce failure and to plan and schedule the harvester operations in optimum time, we have to know how many failures occur in each term of machine performance and to know the mean time between failures.

India has ever been among the major producers of sorghum in the World. The country has been able to maintain its position among the top three producers of the crop. In India sorghum is produced both as a summer and a winter crop (i.e. khariff and rabi). India also maintains a place in the top ten consumers of sorghum in the world with consumption figure of 7.7 million metric tons during 2005-06 (Anonymous, 2007). Harvesting is the important operation in the crop husbandry. Harvesting of sorghum has become a critical operation due to inadequate labour availability. The total harvesting of sorghum requires two stages cutting of plant, one at the top for separating cobs and second at the bottom for fodder. Hence double operation is required for harvesting of this crop. Harvesting of this crop requires considerable amount of labour, drudgery and time. Hence the present study was aimed to develop tractor front mounted sorghum harvester that will cut the cobs and convey to collection box as well as windrow the stalks of sorghum efficiently and economically. To improve the performance of cutting and nipping unit of Sorghum harvester and to analyze the mechanical failure in various parts, the present study was undertaken.

Pareto analysis charts are the graphical tool used in Pareto analysis. These charts were drawn in form of bar chart which indicates the intensity of failure/fault occurred in machine component. The highest intensity of failure in component was shown by tallest bar and next higher failure was represented by next tallest bar and many more. Check sheet is used for collection of data as input for predation of Pareto charts.

\section{Materials and Methods}

The sorghum harvester was tested in different field for different varieties of sorghum using standard methods.During the harvesting operation by the hydraulically operated sorghum harvester, breakage caused a big disturbance while performing the trials in the field. It was concluded that breakage caused were due to sudden increase of speed of operation of the harvester but also the improper material selection for parts, improper dimensions of parts, misalignment of parts and improper clearance between moving parts. Data have been recorded during entire harvesting season of sorghum and found that mostly failure occurred in four operating parts. Thus more emphasis was given on these four parts shown in figure 1 . Sorghum harvester as a system was divided into four subsystems.If every one of subsystems stopped, the whole machine performance would be stopped, thus relation among harvester subsystems is series. The Pareto analysis of various parts of harvester was conducted using standard procedure and results were shown in figures 1 and 2. Pareto chart shows the component in machine have maximum or minimum failures.

\section{Results and Discussion}

Figure 1 shows the Pareto analysis diagram, which represents the different fault/breakages occurred in various part during field operation of part. According to figure eccentric shaft of nipping unit has maximum number of failure i.e. $46.7 \%$ and cutter bar of cutting unit has minimum recorded failure i.e. $6.6 \%$.

Nearly 46.7 per cent of fault occurred in eccentric drive shaft of nipping unit. This 
mainly affects the performance of nipping unit. Some of fault/breakages occurred in other parts like eccentric drive shaft of cutting unit, cutter bar of cutting and nipping unit which are also found during the operation are presented in figures 1 and 2. The Pareto analysis shows that 46.7 percent and 20 per cent failure/ fault occurred in eccentric drive shaft of nipping unit and eccentric drive shaft of cutting unit respectively.

Fig.1 Pareto analysis of breakages in parts of Sorghum harvester

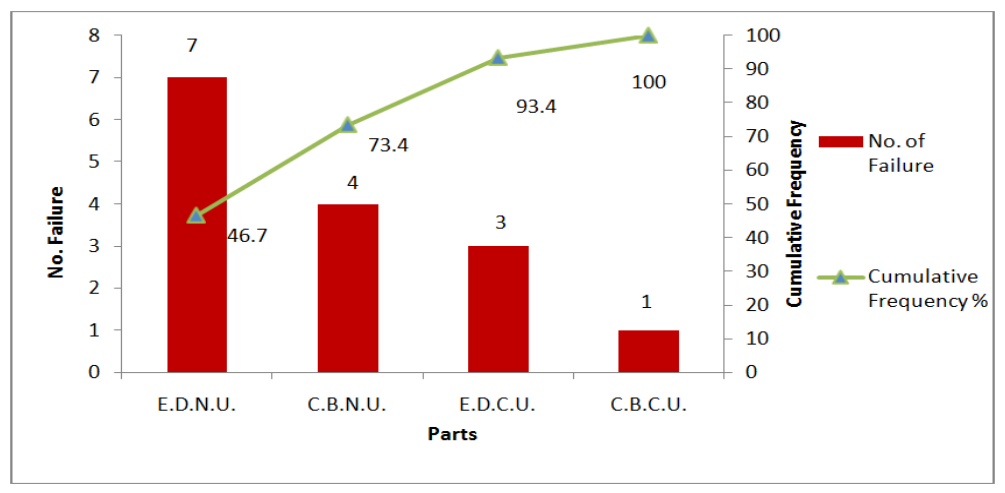

Fig.2 Details of failure of various part of Sorghum harvester during field operation

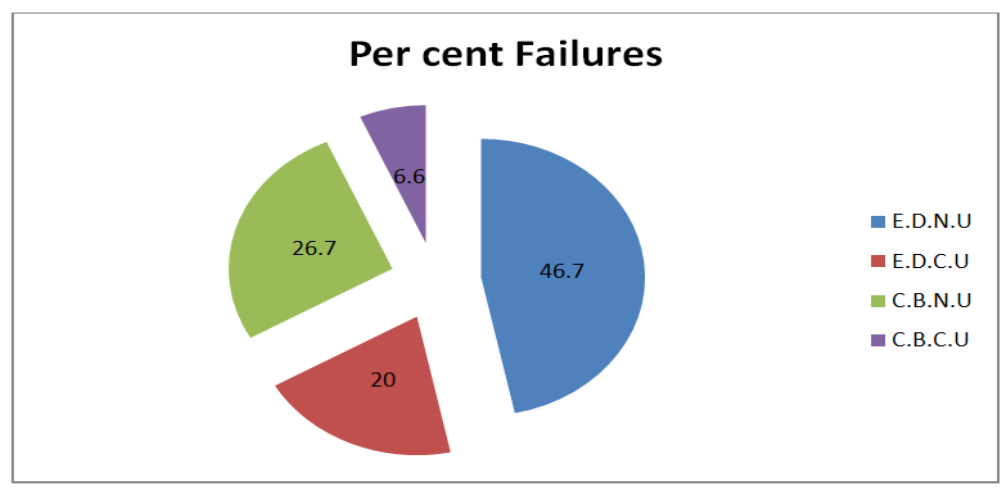

E.D.N.U. - Eccentric Drive Shaft of Nipping Unit

C.B.N.U. - Cutter bar of Nipping Unit

E.D.C.U. - Eccentric Drive Shaft of Cutting Unit

C.B.C.U. - Cutter bar of Cutting Unit

Similarly 26.7 percent and 6.6 percent failure/faults occurred in cutter bar of nipping unit and cutter bar of cutting unit respectively.

In order to control and reduce failures of component and to plan and schedule the harvesting operations in optimum time, machine reliability must be known. Analysis shows that the eccentric drive shaft of nipping unit and eccentric drive shaft of cutting units were most critical component of machine in failure/fault point of view. For minimizing the failure in component proper selection of component material as per recommended load condition is necessary as well as maintain proper clearance and lubrication in moving parts so that favourable operating environment should be maintain and failure/ faults may reduce.

The technique used to analyse the failure occurs in the hydraulic system of the tractor operated sorghum harvester showed the nature of faults 
and the remedies schedule's for the operation. This method of fault analysis may helpful to the machine when in operation.

\section{References}

Anonymous. 2007. GOI, Agriculture statistics at a glance, Directorate of Economics and Statistics. New Delhi, India: Ministry of Agriculture, Government of India.

Allen, R.R. and L.D. Hollingsworth. 1981. Combine header performance in Lodged grain sorghum. Transactions of ASAE, (24): 1426-1428 and 1431.

Barabadi, J., and U. Kumar. 2007. Reliability characteristics based maintenance scheduling: a case study of a crushing plant. Int. J. Performability Eng., 3(3): 319-328.

Barabadi, J., and U. Kumar. 2008. Reliability analysis of mining equipment: a case study of a crushing plant at Jajarm Bauxite mine in Iran. Reliability Eng. Syst. Safety, 93(4): 647-653.

Bartkute, V., and L. Sakalauskas. 2008. The method of three-parameter weibull distribution estimation. Actaet Commentationes Universitatis Tartuensis de Mathematica, 12: 65-78.

Billinton, R., and R.N. Allan. 2012. Reliability evaluation of engineering systems: concepts and techniques. Second edition, New York and London: Plenum press. CIGR, Handbook of Agricultural Engineering Volume III, page: 632.

Hall, R.A., and L.K. Daneshmend. 2010. Reliability modeling of surface mining equipment: data gathering and analysis methodologies. Int. J. Surface Mining Reclamat. Environ., 17(3): 139-155.

Hoseinie, S.H., M. Ataei, R. Khalokakaei, B. Ghodrati, and U. Kumar. 2012. J Quality Maintenance Engi., 18(1): 98-119.

Bedane, G.M., M.L. Gupta and D.L. George. 2008. Development and Evaluation of a Guayule Seed Harvester. Indus. Crops Products, 28: 177-183.

Bhende, S.M. and M.A. Bhamodkar. 2006. Hydrostatic drive system for sorghum harvester. New Agriculturist, 17(1,2): 207-214.

Charyulu, D.K., M.C.S. Bantilan, S. Nedumaran and U.K. Deb. 2011. Development and Diffusion of Improved Sorghum Cultivars in India: Impact on Growth and Variability in Yield (ICRISAT).

Joshi, A. and P. Kadam. 2014. An application of pareto analysis and cause effect Diagram for minimization of defects in manual Casting process. Int. J. Mech. Production Engi., ISSN: 2320-2092, Volume- 2, Issue- 2.

Kanafojski, C.L. and J. Karwowski. 1976. Agricultural machines, theory and construction. Vol. 2 Foreign scientific publication Department of the National Center for Scientific Technical and Economic information, Warsaw, Polland: $141-228$ and $627-726$.

Mohiuddin Ahmed and Nafis Ahmad. 2011. An Application of Pareto Analysis and Cause-and-Effect Diagram (CED) for Minimizing Rejection of Raw Materials in Lamp Production Process. Manag. Sci. Eng., 5(3): 87-95.

\section{How to cite this article:}

Nikam, M.D., S.H. Thakare, V.P. Khambalkar and Karhale, S.S. 2017. Analysis of Failure of Hydraulic Operated Sorghum Harvester. Int.J.Curr.Microbiol.App.Sci. 6(6): 1218-1221. doi: https://doi.org/10.20546/ijcmas.2017.606.141 